\title{
Risky Sexual Behavior and Associated Factors among Adolescents Aged 15-19 Years at Governmental High Schools in Aksum Town, Tigray, Ethiopia, 2019: An Institution-Based, Cross- Sectional Study
}

\author{
Mengesha Srahbzu $\mathbb{D}^{1}$ and Enguday Tirfeneh $\mathbb{D}^{2}$ \\ ${ }^{1}$ Department of Psychiatry, College of Medicine and Health Science, University of Gondar, Ethiopia \\ ${ }^{2}$ Department of Psychiatry College of Health Sciences and Comprehensive Specialized Hospital, Aksum University, Ethiopia \\ Correspondence should be addressed to Mengesha Srahbzu; mengusew@gmail.com
}

Received 10 May 2020; Revised 23 July 2020; Accepted 11 August 2020; Published 21 August 2020

Academic Editor: Valeria Cavalcanti Rolla

Copyright (C) 2020 Mengesha Srahbzu and Enguday Tirfeneh. This is an open access article distributed under the Creative Commons Attribution License, which permits unrestricted use, distribution, and reproduction in any medium, provided the original work is properly cited.

\begin{abstract}
Introduction. The impact of risky sexual practice on the general health of adolescents is enormous; little attention has been given on identification and intervention plans. Therefore, the aim of this study was to find the magnitude of risky sexual behavior and associated factors among adolescents aged 15-19 years in high schools at Aksum town, Tigray, Ethiopia. Methods. An institution-based cross-sectional study was conducted at governmental high schools of Aksum town. We recruited a total of 659 adolescents aged 15-19 years by using a systematic random sampling technique. Data was collected with a face-to-face interview. An Amharic version of the sexual risk behavior scale was used to measure risky sexual behaviors. The patient health questionnaire 9, the Oslo-3 social support scale, and an adverse childhood experience questionnaire were used to assess the factors. The coded data were entered into EpiData v.4.1 and analyzed using Statistical Package for the Social Sciences version 22. Bivariate and multivariate logistic regressions were done. An adjusted odds ratio at a $p$ value $<0.05$ with $95 \%$ confidence interval was taken to declare statistical significance. Result. A total of 644 students have participated with a response rate of 97.7\%. The prevalence of risky sexual behavior among adolescents aged 15-19 years was found to be 17.2\%. Factors like poor social support $(\mathrm{AOR}=5.59,95 \% \mathrm{CI}: 2.71-11.53)$, living out of family $(\mathrm{AOR}=1.93,95 \% \mathrm{CI}$ : 1.21-3.07), experiencing parental neglect $(\mathrm{AOR}=1.87,95 \% \mathrm{CI}: 1.18-2.94)$, and drinking alcohol $(\mathrm{AOR}=2.55,95 \% \mathrm{CI}: 1.55-4.20)$ were statistically associated with risky sexual behavior. Conclusion and Recommendations. The prevalence of risky sexual behavior was found to be alarming among adolescents of high school aged 15-19 years. This can significantly affect health quality in the community and the country at large. We recommend setting strategies that are against the determining factors of risky sexual behavior; the control of alcoholic beverages among adolescents aged 15-19 years must be enhanced, and awareness creation must be made regarding its unpleasant consequences.
\end{abstract}

\section{Introduction}

Adolescence is a critical age in which people need to undergo sexual development [1]. Many health risks and complications secondary to unprotected sexual activity among adolescents have been documented by the World Health Organization (WHO) $[2,3]$, for which interventions should be imple- mented promptly. Recent data indicated that 1.2 billion people in the world are adolescents aged 10-19 years [4].

Adolescents are slightly at an increased level of vulnerability for different health conditions including sexually transmitted diseases when compared to the adult population [5]. Risky sexual behavior is characterized by different hazardous behaviors such as premarital sex, multiple sexual partners, 
and unprotected sex. Such hazardous sexual behaviors are reported to end up with unpleasant health outcomes like HIV/AIDS, unwanted pregnancies, and unsafe abortions [6].

Health problems among adolescents including sexually transmitted infections linked with socioeconomic disadvantages seem to be increasing. Incidence and prevalence estimates indicated that one in four sexually active adolescent women has sexually transmitted infections such as chlamydia or human papillomavirus [7]. Compared with older adults, sexually active adolescents aged 15-19 years are at higher risk of acquiring sexually transmitted infections for the combination of behavioral, biological, and cultural reasons [8].

Unsafe sexual behavior and the associated exposure to infection is one of the major causes of preventable mortality in low-income countries (after childhood underweight and unsafe water) [9]. It is the major means of transmission for HIV/AIDS and human papillomavirus, with overall mortality more than one million people worldwide [10]. Among the means of transmission for HIV/AIDS in each state of America, the primary one is risky sexual behavior [11].

Pieces of literature have measured and reported the size of risky sexual behavior, and it ranges from 21.6 to $42.1 \%$ using different screening tools [12-15]. In one crosssectional study conducted in the eastern part of Ethiopia among high school and preparatory students, they reported a $13.7 \%$ prevalence of risky sexual behavior [16].

Few studies have revealed its association with smoking, alcohol, and drug abuse, which are also considered risky behaviors or substance abuse. Shreds of evidence indicated that those adolescents who have experienced abuse by others and had antisocial behaviors have been found to have an increased chance of involving in risky sexual activities [17, 18].

Socioeconomic status, joblessness, sexually active friends, family instability, single-parent household, sibling sexual activity, and each characteristic (race, gender, age, and puberty status) have all been associated with adolescent risky sexual behavior [19].

Even though little is known about the size of risky sexual behavior, its size has been given little attention among adolescents particularly those aged 15-19 years. Understanding sexual behavior and its determinants among adolescents aged 15-19 years is crucial to come up with effective intervention. Therefore, this study investigated the magnitude of risky sexual behavior and its correlates among adolescents aged 15-19 years.

\section{Materials and Methods}

2.1. Study Design, Area, and Period. We conducted an institution-based cross-sectional study design among adolescents aged 15-19 years at governmental high schools in Aksum town, Tigray, Ethiopia. There are three governmental high schools in Aksum town named Kedamay-Minilik secondary school, Atse-Kaleb secondary school, and Aksum secondary school. A total of 2579 grade nine and 2241 grade ten students aged 15-19 years were attending their regular classes in the three high schools. Data were collected from January 1 to $30,2019$.
2.2. Sample Size Determination and Sampling Procedure. We calculated the sample size by using the single population proportion formula by taking the following assumptions: $1.96, Z$ (normal distribution), 95\% confidence interval (CI) of certainty $(a=0.05)$, and a $5 \%$ marginal error. The proportion of risky sexual behavior was taken to be $51.3 \%$ from the previous study [20] and a 10\% nonresponse rate. Therefore, based on the assumptions, the final sample size was taken to be 659 .

A systematic random sampling technique was used to select a total of 659 adolescent participants aged 15-19 years during the study period. We considered all adolescent students aged 15-19 years in Aksum town in 2019 as a source population and all adolescent students aged 15-19 years during the data collection period as a study population. All students aged 15-19 years who already registered on the list were included, and those students aged 15-19 years who were critically sick during data collection and unable to communicate were excluded from the study.

2.3. Outcome Variable. The outcome variable for this study was risky sexual behavior. It was measured by a five-item screening tool that was prepared by adopting the World Health Organization Sexual and Reproductive Health (SRH) questionnaire for local-based scenarios. The screening tool was used before in our country, and reliability Cronbach's alpha was reported to be 0.92 [16]. The sexual risk behavior scale (SRBS) was used to assess the lifetime risky sexual activities of the adolescents. The items ask about the presence or absence of vaginal sexual intercourse, early sexual debut (before 14 years of age), having multiple sexual partners, having HIV testing, and inconsistent condom use in their sexual practices. Adolescents aged 15-19 years who have practiced in at least one were considered positive for risky sexual behavior [16].

\subsection{Independent Variables}

2.4.1. Sociodemographic Factors. Sociodemographic variables included age, sex, religion, ethnicity, educational level, residence, number of children, the educational status of the mother, educational status of the father, and occupational status of fathers and mothers.

2.4.2. Depression and Parental Neglect. Public health questionnaire 9 (PHQ-9) was used to assess depression which is a multipurpose instrument for screening, diagnosing, monitoring, and measuring the severity of depression. Those who scored $>5$ from the PHQ- 9 scale were considered possibly positive for depression [21]. The adverse childhood experience questionnaire which is a 10 -item screening tool was used to access parental neglect. The adverse childhood experience questionnaire includes questions that assess emotional abuse and neglect, physical abuse and neglect, educational and medical neglect, and sexual abuse [22].

2.4.3. Social Support and Substance-Related Factors. The level of social support was assessed by the Oslo-3 social support scale. The scale divides the level of social support into three as poor social support (3-8), moderate social 
support (3-14), and strong social support (12-14) (reliability Cronbach's $\alpha=0.91$ ) [23]. Substance use history (alcohol, khat, and cigarette) was assessed by yes/no questions for current use and lifetime use.

2.5. Data Collection Procedure. Data were collected as selfreported using a structured questionnaire. The study subjects were informed about the general information about the study objectives as well as the opportunities or benefits that this study could bring. Finally, the filled questionnaires were checked for consistency and completeness daily. To assure the data quality, high emphasis was given in designing data collection instruments. Structured and pretested questionnaires were used to collect information. The overall questionnaires were prepared in English, and it was translated to the local language "Tigrigna"; finally, we translated it back to English to check the consistency of the information to be collected. The training was given for data collectors and supervisors by the principal investigator on the methods of data collection for two days. The questionnaire was pretested one week before the actual data collection on $5 \%$ of the total same size that was not included in the main survey.

2.6. Data Processing and Analysis. The entire questionnaires were checked for completeness and entered into EpiData 4.1 , and then, it was exported to SPSS 22 version statistical software for analysis. Descriptive statistics, bivariate analysis, and multivariate logistic regression were conducted. The sociodemographic characteristics of respondents were analyzed by descriptive statistics. Univariate analysis was used to see the association between risky sexual behavior and independent variables. Variables whose $p$ value is $<0.2$ were entered to multivariate logistic regression to control confounding effect. The significance was declared at $p$ value $<$ 0.05 . To determine the strength of association between dependent and independent variables, the adjusted odds ratio at a $95 \%$ confidence interval was used.

\section{Result}

3.1. Sociodemographic Characteristics. A total of 644 individuals aged 15-19 years participated in the study with a response rate of $97.7 \%$. More than half 55\% (354) of the study participants were female students. The majority of participants, $78.6 \%$ (506) of study participants, were Orthodox Christian followers by religion. Regarding educational levels of students, $53.2 \%$ (336) were grade nine students and the rest $47.8 \%$ (308) of them were grade ten students. Onethird $(67.1 \%)$ of the study participants were from urban in their residence (Table 1 ).

3.2. Social Support-Related Factor. As measured by the threeitem Oslo social support scale, 46.4\% (299) of adolescents aged 15-19 years lay in the poor social support level followed by moderate social support which was 32\% (206). The rest have been found to lay in a strong or good social support level (Figure 1).

3.3. Substance Use-Related Factors. Among participants of this study, most students used alcoholic beverages both in
TABLE 1: Sociodemographic characteristics of adolescents aged 1519 years at high schools in Aksum town, Tigray, Ethiopia, 2019 $(n=644)$.

\begin{tabular}{|c|c|c|c|}
\hline Variables & Category & Frequency & Percentage \\
\hline \multirow{2}{*}{ Sex } & Male & 290 & 45 \\
\hline & Female & 354 & 55 \\
\hline \multirow{2}{*}{ Educational level } & Grade 9 & 336 & 52.2 \\
\hline & Grade 10 & 308 & 47.8 \\
\hline \multirow{3}{*}{ Religion } & Orthodox Christian & 512 & 79.5 \\
\hline & Muslim & 106 & 16.5 \\
\hline & Protestant Christian & 26 & 4 \\
\hline \multirow{2}{*}{ Residence } & Urban & 432 & 67.1 \\
\hline & Rural & 212 & 32.9 \\
\hline \multirow{5}{*}{$\begin{array}{l}\text { Fathers' } \\
\text { educational } \\
\text { status }\end{array}$} & No formal education & 86 & 13.4 \\
\hline & 1-4th grade & 169 & 26.2 \\
\hline & 5 -8th grade & 146 & 22.7 \\
\hline & 9-12th grade & 113 & 17.5 \\
\hline & Above 12 th grade & 130 & 20.2 \\
\hline \multirow{5}{*}{$\begin{array}{l}\text { Mothers' } \\
\text { educational } \\
\text { status }\end{array}$} & No formal education & 180 & 28 \\
\hline & $1-4$ th grade & 143 & 22.2 \\
\hline & $5-8$ th grade & 128 & 19.9 \\
\hline & 9-12th grade & 121 & 18.8 \\
\hline & Above 12th grade & 72 & 11.2 \\
\hline \multirow{4}{*}{$\begin{array}{l}\text { Fathers' } \\
\text { occupation }\end{array}$} & Farmer & 228 & 35.4 \\
\hline & Daily laborer & 34 & 5.3 \\
\hline & Merchant & 114 & 17.7 \\
\hline & $\begin{array}{c}\text { Governmental/private } \\
\text { employee }\end{array}$ & 268 & 41.6 \\
\hline \multirow{5}{*}{$\begin{array}{l}\text { Mothers' } \\
\text { occupation }\end{array}$} & Farmer & 182 & 28.3 \\
\hline & Daily laborer & 38 & 5.9 \\
\hline & Merchant & 78 & 12.1 \\
\hline & $\begin{array}{c}\text { Governmental/private } \\
\text { employee }\end{array}$ & 203 & 31.6 \\
\hline & Housewife & 143 & 22.2 \\
\hline \multirow{2}{*}{ Family size } & $1-5$ & 378 & 58.7 \\
\hline & $>5$ & 266 & 41.3 \\
\hline
\end{tabular}

their lifetime and within the last three months of the study time (Figure 2).

3.4. Clinically Related Factors. Among the total participants of this study, $28.9 \%$ of them have been found to have possible depression as screened by PHQ-9. Parental treatments towards adolescents were also screened, and the result indicated that about $36.5 \%$ of the students reported that they are neglected by their parents, caregivers, or guardians during the study time.

3.5. Prevalence of Risky Sexual Behavior and Associated Factors. According to our study, the overall prevalence of risky sexual behavior among adolescents aged 15-19 years at high schools in Aksum town was found to be $17.2 \%$ (95\% CI; 14.3\%, 20.2\%). Among the total 354 female participants, risky sexual behavior is $16.1 \%(57 / 354)$ whereas it is 


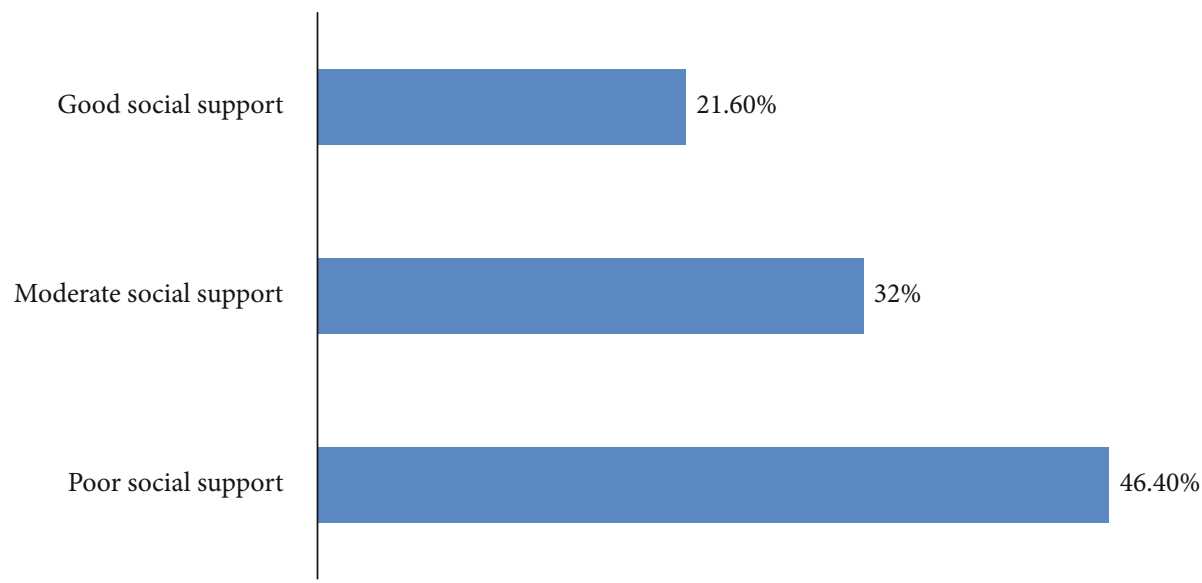

FIGURE 1: Distribution of social support-related factors among adolescents aged 15-19 years at high schools in Aksum town, Tigray, Ethiopia, 2019.

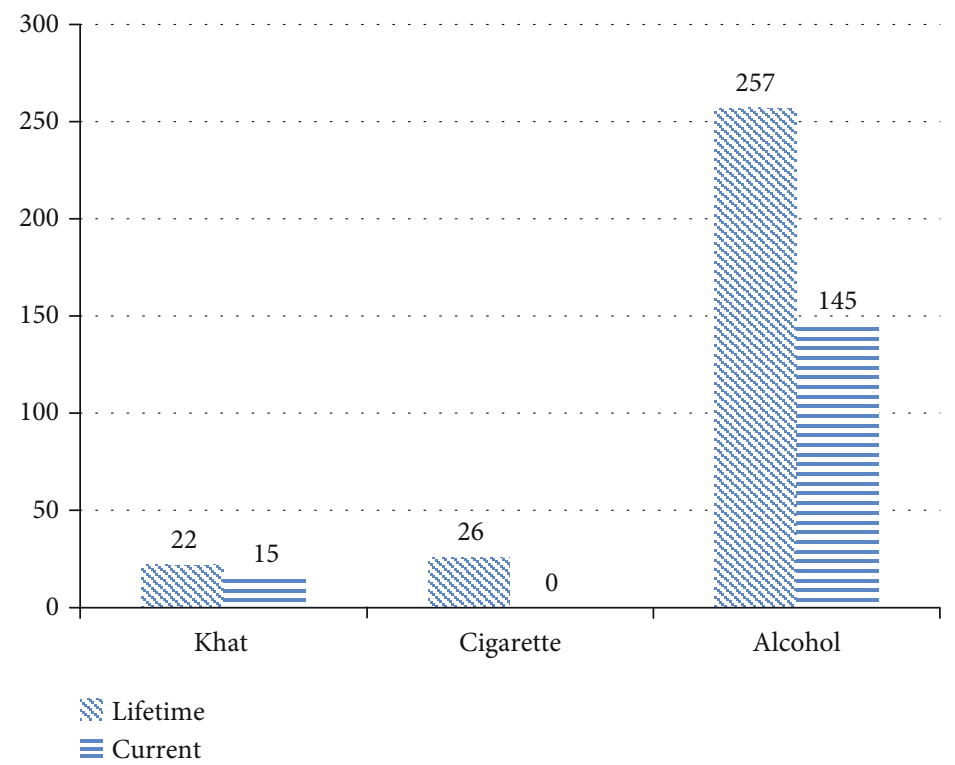

Figure 2: Distribution of substance use-related factors among adolescents aged 15-19 years at high schools in Aksum town, Tigray, Ethiopia, 2019.

found to be $18.6 \%(54 / 290)$ in males. A high degree of occurrence in the prevalence of risky sexual behavior has been observed among those who were following grade nine when compared to those who were following grade ten during the study period. On the contrary, almost the same degree of occurrence of risky sexual behavior has been observed between those who were from urban and rural (Figure 3).

Regarding factors associated with risky sexual behavior of study participants, bivariate logistic regression was done to identify candidate factors for multivariate logistic regression analysis. These factors have been selected at $p$ value $<0.25$. After controlling for confounding effect by multivariate logistic regression, factors like poor social support, living out of the family, experiencing parental neglect, and current alcohol use are associated with risky sexual behavior of study participants at $p$ value $<0.05$.
Those adolescent students aged 15-19 years who have poor social support were 5.59 times more likely to participate in risky sexual behavior as compared to those who have strong social support $(\mathrm{AOR}=5.59,95 \% \mathrm{CI}$ : 2.71-11.53). Another variable that was found to be associated with risky sexual behavior was living without a family member. Students who were living out of their family members were 1.93 times more likely to participate in risky sexual behavior when compared to those who were living with their family $(\mathrm{AOR}=1.93,95 \%$ CI: 1.21-3.07).

Adolescent students aged 15-19 years who experienced parental neglect by their primary caregivers were also among those who were found to have a significant association with risky sexual behavior. The probability of participating in risky sexual behavior was found to be increased by $87 \%$ in adolescents aged 15-19 years who experienced parental 


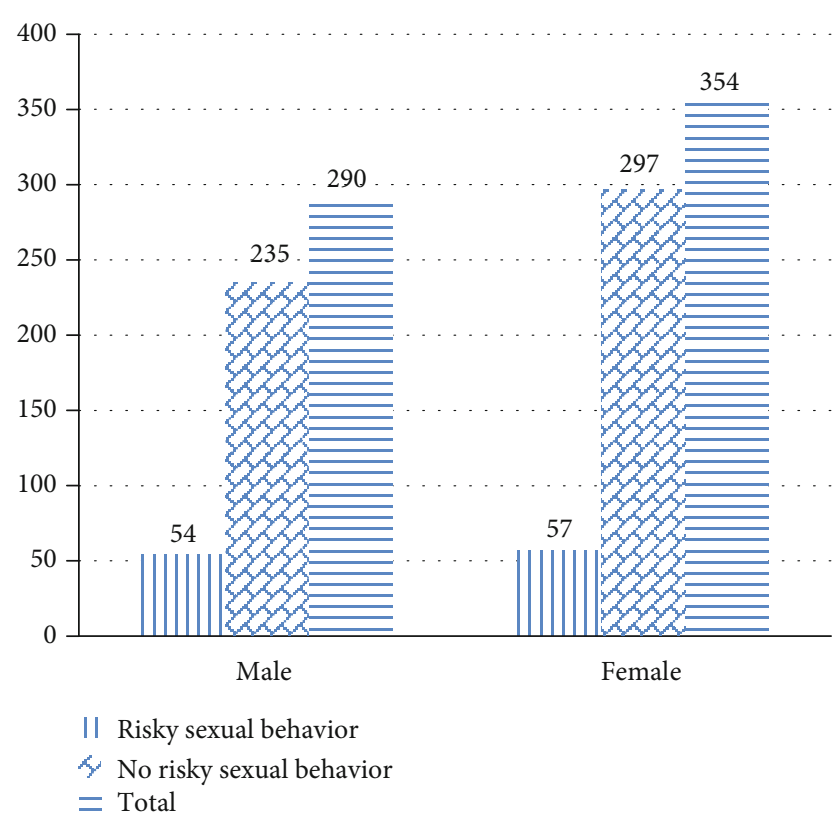

FIgURE 3: Distribution of prevalence of risky sexual behavior with sex of participants among adolescents aged 15-19 years at high schools in Aksum town, Tigray, Ethiopia, 2019.

neglect when compared to those adolescents aged $15-19$ years who did not experience $(\mathrm{AOR}=1.87,95 \% \mathrm{CI}$ : 1.18-2.94).

Those who were drinking alcoholic beverages were 2.55 times more likely to have risky sexual behavior than those who did not drink $(\mathrm{AOR}=2.55,95 \% \mathrm{CI}$ : 1.55-4.20) (Table 2).

\section{Discussion}

4.1. Discussion on the Prevalence of Risky Sexual Behavior. Our study tried to add knowledge regarding the magnitude of risky sexual behavior and factors which may have an impact on the possibility of participating in such behavior among this special population.

The overall prevalence of risky sexual behavior among adolescent students aged 15-19 years in our study was $17.2 \%$. Our study result is consistent with other studies conducted in Northwest Ethiopia among high school students and reported $19.8 \%$ [24], and $17.9 \%$ on a study done at Bodti, Ethiopia [25]. However, our study result regarding the prevalence of risky sexual behavior among adolescents aged 15-19 years is lower than that of the previous studies conducted in different parts of the world such as $51.3 \%$ in Mizan Tepi [20], Ethiopia; 43.1\% in Addis Ababa [26]; $44.9 \%$ at Bahir Dar, Ethiopia [6]; 40.6\% in another Bahir Dar, Ethiopia, study [27]; and 54\% in the rural part of Cameroon [28]. This disparity might be due to the difference in study participants, in which adult construction works and college-level students were mainly considered in studies conducted at Bahir Dar, Ethiopia; preparatory students were also included in a study done at Mizan Tepi, Ethiopia; clinical patients were studied at Addis Ababa; and only female students were studied in a Cameroon study.
Another possible reason for such difference might also be the cultural influence on adolescents and problems on their degree of openness to report their sexual practices even it was self-reporting.

On the other hand, the current study finding for risky sexual behavior among adolescents aged 15-19 years was higher than that of the study conducted among adolescents at Humera, Ethiopia, $13.7 \%$. This disparity might be due to the difference in the study participants, in which preparatory school students were also included in a study at Benishangul Gumuz, Ethiopia [24]. This might also be due to the difference in sample size, in which only 422 students were included in the study conducted at Humera, Ethiopia [16].

4.2. Discussion on Factors Associated with Risky Sexual Behavior. Those adolescents aged 15-19 years who have poor social support were 5.59 times more likely to participate in risky sexual behavior when compared to those who have strong social support. This might be because the absence of supportive and caring relationships with families and other school communities leads adolescents to poor academic achievement. This poor academic failure is one of the major contributing factors in participation in risky health behavior [29]. This is supported by different studies [30-32].

Adolescents aged 15-19 years who were living without their family were 1.93 times more likely to have risky sexual behavior when compared to those who live with their families. This might be because adolescent age group close family supervision hinders them from participating in different risky behaviors particularly sexual activities. This might also be due to the reason that peer pressures get stronger to influence and make them participate in such risky behaviors when their close family member is not around [33]. This study was supported by different studies conducted earlier in different areas [16].

This study further explored that the risk of participating in risky sexual activities increased by $87 \%$ in those adolescents aged 15-19 years who experienced parental neglect by their primary caregiver when compared to adolescents aged 15-19 years who did not. This might be due to the increased emotional disturbances soon as they experience neglect which leads them to participate in risky behaviors as a defense mechanism [34, 35]. Different studies conducted earlier are alongside this study.

Moreover, this study declared that using alcoholic beverages has a significant influence on the fate of participation in risky sexual activities. Those adolescents aged 15-19 years who used alcohol within three months before the start of the study period were 2.55 times more likely to participate in risky sexual activities than those who did not use alcohol. This might be because almost all mental functions get lowered by the effects of alcohol. This does not give them the chance to comprehend things that put them at potential risk to engage in risky behaviors. This might also be because alcohol use has been linked to early sexual debut and increased likelihood of adolescents being sexually active while they are at school $[36,37]$. This study has been supported by other studies $[36,37]$. 
TABLE 2: Bivariate and multivariate logistic analysis of factors associated with risky sexual behavior among adolescents aged 15-19 years at high schools in Aksum town, Tigray, Ethiopia, $2019(n=644)$.

\begin{tabular}{|c|c|c|c|c|c|}
\hline \multirow[t]{2}{*}{ Variables } & \multirow{2}{*}{ Category } & \multicolumn{2}{|c|}{$\begin{array}{c}\text { Risky sexual } \\
\text { behavior }\end{array}$} & \multirow[t]{2}{*}{ COR $(95 \% \mathrm{CI})$} & \multirow[t]{2}{*}{$\operatorname{AOR}(95 \% \mathrm{CI})$} \\
\hline & & Yes & No & & \\
\hline \multirow{2}{*}{ Educational level } & Grade 9 & 65 & 271 & 1 & 1 \\
\hline & Grade 10 & 46 & 262 & $0.73(0.49,1.11)$ & $0.72(0.49,1.13)$ \\
\hline \multirow{3}{*}{ Social support } & Poor & 214 & 85 & $5.12(2.57,10.22)$ & $5.59(2.71,11.53)^{* * *}$ \\
\hline & Moderate & 190 & 16 & $1.09(0.48,2.47)$ & $1.27(0.54,2.97)$ \\
\hline & Strong & 129 & 10 & 1 & 1 \\
\hline \multirow{2}{*}{ Living with family member } & Yes & 63 & 381 & 1 & 1 \\
\hline & No & 48 & 152 & $1.91(1.26,2.91)$ & $1.93(1.21,3.07)^{* *}$ \\
\hline \multirow{2}{*}{ Depression } & Yes & 42 & 144 & $1.64(1.07,2.52)$ & $1.21(0.74,1.98)$ \\
\hline & No & 69 & 389 & 1 & 1 \\
\hline \multirow{2}{*}{ Parental neglect } & Yes & 54 & 181 & $1.84(1.22,2.79)$ & $1.87(1.18,2.94)^{* *}$ \\
\hline & No & 57 & 352 & 1 & 1 \\
\hline \multirow{2}{*}{ Current alcohol use } & Yes & 41 & 104 & $2.42(1.56,3.76)$ & $2.55(1.55,4.20)^{* * *}$ \\
\hline & No & 70 & 429 & 1 & 1 \\
\hline \multirow{2}{*}{ Lifetime cigarette smoking } & Yes & 12 & 14 & $4.94(2.02,10.01)$ & $4.52(0.92,22.19)$ \\
\hline & No & 99 & 519 & 1 & 1 \\
\hline \multirow{2}{*}{ Current cigarette smoking } & Yes & 8 & 12 & $3.37(1.35,8.46)$ & $0.29(0.05,1.83)$ \\
\hline & No & 103 & 521 & 1 & 1 \\
\hline \multirow{5}{*}{ Fathers' educational status } & No formal education & 15 & 71 & $1.75(0.80,3.84)$ & $0.86(0.36,2.04)$ \\
\hline & 1-4th grade & 27 & 142 & $1.58(0.79,3.14)$ & $1.04(0.49,2.18)$ \\
\hline & 5-8th grade & 26 & 120 & $1.80(0.89,3.61)$ & $1.15(0.54,2.44)$ \\
\hline & $9-12$ th grade & 29 & 84 & $2.86(1.43,5.74)$ & $1.92(0.89,4.14)$ \\
\hline & Above 12th grade & 14 & 116 & 1 & 1 \\
\hline
\end{tabular}

${ }^{* *} p$ value $<0.01 ;{ }^{* * *} p$ value $<0.001$

\section{Conclusion and Recommendation}

This study has declared that an alarming proportion of adolescent students aged 15-19 years have participated in risky sexual behavior. This can significantly affect the quality of health in the community and the country at large. Factors, like having poor social support, living out of the family, experiencing parental neglect, and using alcoholic beverages, are risk factors that increase the odds of risky sexual behavior among adolescent students aged 15-19 years.

An action shall be taken which are against the factors found to increase the odds of risky sexual behavior to protect the health of students aged 15-19 years while they are at school. We would like also to recommend that the control of alcoholic beverages among adolescents aged 15-19 years must be enhanced and awareness creation must be made regarding its unpleasant consequences, especially on these special populations.

\section{Data Availability}

The source data included in the manuscript can be accessed from the corresponding author Mengesha Srahbzu upon request through email address of mengusew@gmail.com.

\section{Ethical Approval}

Ethical approval was obtained from the ethical review board of the Institute of Health, Aksum University.

\section{Consent}

Written consent was asked from each selected student after they are informed about the nature, purposes, benefits, and adverse effects of the study and invited to participate. Written assent was also obtained from those who are under 18 years old from their parents/guardians/teachers. Confidentiality was ensured. Participants were strictly informed as they have the right to refuse or discontinue participation at any time.

\section{Conflicts of Interest}

The authors declare that they have no competing interest.

\section{Acknowledgments}

First, we would like to thank Aksum University for granting the research financially and materially for the process of data collection, entry, and analysis. We would like to extend our 
heartfelt thanks to Aksum University College of health science research office and ethical review committee for their timely cooperation. We would like also to raise our thanks to the Aksum town education office and each governmental high school head office for their cooperation during the data collection period. In addition, we would like to thank Mr. Admasu Belay who helped us in reviewing the document for English language. This study was funded by Aksum University for the process of data collection and analysis.

\section{References}

[1] R. Blum and K. Mmari, Risk and protective factors affecting adolescent reproductive health in developing countries: an anal$y$ sis of adolescent sexual and reproductive health literature from around the world, Summary, 2004.

[2] Organization, WH, Young people: health risks and solutions, WHO, 2011, April, 2019.

[3] V. Chandra-Mouli, A. V. Camacho, and P.-A. Michaud, "WHO guidelines on preventing early pregnancy and poor reproductive outcomes among adolescents in developing countries," Journal of Adolescent Health, vol. 52, no. 5, pp. 517-522, 2013.

[4] Organization, WH, Adolescent health, 2019, July 2020, https:// www.who.int/health-topics/adolescents/coming-of-ageadolescent-health.

[5] J. Nicholson, Risky Sexual Behaviour among Adolescents and Young Adults, University of North Carolina Chapel Hill, 2012.

[6] Z. Alamrew, M. Bedimo, and M. Azage, Risky sexual practices and associated factors for HIVIAIDS infection among private college students in Bahir Dar City, ISRN Public Health, Northwest Ethiopia, 2013.

[7] S. E. Forhan, S. L. Gottlieb, M. R. Sternberg et al., "Prevalence of sexually transmitted infections among female adolescents aged 14 to 19 in the United States," Pediatrics, vol. 124, no. 6, pp. 1505-151ss2, 2009.

[8] E. C. Tilson, V. Sanchez, C. L. Ford et al., "Barriers to asymptomatic screening and other STD services for adolescents and young adults: focus group discussions," BMC Public Health, vol. 4, no. 1, p. 21, 2004.

[9] Organization, WH, ECOSOC meeting addressing noncommunicable diseases and mental health: major challenges to sustainable development in the 21st century, World Health Organization, 2009.

[10] C. Anderson, M. F. Gallo, T. Hylton-Kong et al., "Randomized controlled trial on the effectiveness of counseling messages for avoiding unprotected sexual intercourse during sexually transmitted infection and reproductive tract infection treatment among female sexually transmitted infection clinic patients," Sexually Transmitted Diseases, vol. 40, no. 2, pp. 105-110, 2013.

[11] Organization, WH, Report on Global Sexually Transmitted Infection Surveillance 2018, WHO, 2018.

[12] M. Abebe, A. Tsion, and F. Netsanet, "Living with parents and risky sexual behaviors among preparatory school students in Jimma zone, South west Ethiopia," African Health Sciences, vol. 13, no. 2, pp. 498-506, 2013.

[13] G. Tura, F. Alemseged, and S. Dejene, "Risky sexual behavior and predisposing factors among students of Jimma University, Ethiopia," Ethiopian Journal of Health Sciences, vol. 22, no. 3, 2012 .
[14] N. Fentahun and A. Mamo, "Risky sexual behaviors and associated factors among male and female students in Jimma Zone preparatory schools, South West Ethiopia: comparative study," Ethiopian Journal of Health Sciences, vol. 24, no. 1, pp. 59-68, 2014.

[15] E. L. Negeri, “Assessment of risky sexual behaviors and risk perception among youths in Western Ethiopia: the influences of family and peers: a comparative cross-sectional study," BMC Public Health, vol. 14, no. 1, p. 301, 2014.

[16] A. F. Dadi and F. G. Teklu, "Risky sexual behavior and associated factors among grade 9-12 students in Humera secondary school, western zone of Tigray, NW Ethiopia, 2014," Science Journal of Public Health, vol. 2, no. 5, pp. 410-416, 2014.

[17] L. K. Lee, P. C. Chen, K. K. Lee, and J. Kaur, "Premarital sexual intercourse among adolescents in Malaysia: a cross-sectional Malaysian school survey," Singapore Medical Journal, vol. 47, no. 6, pp. 476-481, 2006.

[18] M.-L. Wong, R. K. W. Chan, D. Koh et al., "Premarital sexual intercourse among adolescents in an Asian country: multilevel ecological factors," Pediatrics, vol. 124, no. 1, pp. e44-e52, 2009.

[19] Organization, WH, Programming for adolescent health and development: report of a WHO/UNFPA/UNICEF study group on programming for adolescent health, World Health Organization, 1999.

[20] T. E. Yarinbab, N. Y. Tawi, I. Darkiab, F. Debele, and W. A. Ambo, "Risky sexual behaviors and associated factors among students of mizan aman college of health science, Southwest Ethiopia: cross-sectional study," JOJ Nursing and Health Care, vol. 8, no. 3, 2017.

[21] M. David Bienenfeld, Sreening Tests for Depression, Medscape, 2016.

[22] A. Murphy, M. Steele, S. R. Dube et al., "Adverse childhood experiences (ACEs) questionnaire and adult attachment interview (AAI): implications for parent child relationships," Child Abuse \& Neglect, vol. 38, no. 2, pp. 224-233, 2014.

[23] T. Abiola, O. Udofia, and M. Zakari, "Psychometric properties of the 3-item Oslo social support scale among clinical students of Bayero University Kano, Nigeria," Malaysian Journal of Psychiatry, vol. 22, no. 2, pp. 32-41, 2013.

[24] M. Agajie, T. Belachew, T. Tilahun, and M. Amentie, "Risky sexual behavior and associated factors among high school youth in Pawe Woreda, Benishangul Gumuz Region," Science Journal of Clinical Medicine, vol. 4, no. 4, pp. 67-75, 2015.

[25] D. Daka and D. Shaweno, "Magnitude of risky sexual behavior among high school adolescents in Ethiopia: a cross-sectional study," Journal of Public Health and Epidemiology, vol. 6, no. 7, pp. 211-215, 2014.

[26] N. Fetene and W. Mekonnen, "The prevalence of risky sexual behaviors among youth center reproductive health clinics users and non-users in Addis Ababa, Ethiopia: a comparative cross-sectional study," PLoS One, vol. 13, no. 6, article e0198657, 2018.

[27] W. Mulu, M. Yimer, and B. Abera, "Sexual behaviours and associated factors among students at Bahir Dar University: a cross sectional study," Reproductive Health, vol. 11, no. 1, p. 84, 2014.

[28] E. E. Tarkang, "Sexual risk behaviours of high school female learners in Mbonge subdivision of rural Cameroon," Pan African Medical Journal, vol. 20, no. 1, 2015. 
[29] R. Crosnoe, "Social capital and the interplay of families and schools," Journal of Marriage and Family, vol. 66, no. 2, pp. 267-280, 2004.

[30] Z. T. Dimbuene and B. K. Defo, "Risky sexual behaviour among unmarried young people in Cameroon: another look at family environment," Journal of Biosocial Science, vol. 43, no. 2, pp. 129-153, 2011.

[31] K. L. Donahue, B. M. D'Onofrio, J. E. Bates, J. E. Lansford, K. A. Dodge, and G. S. Pettit, "Early exposure to parents' relationship instability: implications for sexual behavior and depression in adolescence," Journal of Adolescent Health, vol. 47 , no. 6 , pp. 547-554, 2010.

[32] D. C. McBride, M. C. Freier, G. L. Hopkins et al., "Quality of parent-child relationship and adolescent HIV risk behaviour in St. Maarten," AIDS Care, vol. 17, Supplement 1, pp. 4554, 2006.

[33] A. Cherie and Y. Berhane, "Peer pressure is the prime driver of risky sexual behaviors among school adolescents in Addis Ababa, Ethiopia," World Journal of AIDS, vol. 2, no. 3, pp. 159-164, 2012.

[34] R. E. Norman, M. Byambaa, R. de, A. Butchart, J. Scott, and T. Vos, "The long-term health consequences of child physical abuse, emotional abuse, and neglect: a systematic review and meta-analysis," PLoS Medicine, vol. 9, no. 11, article e1001349, 2012.

[35] H. L. MacMillan and C. Munn, "The sequelae of child maltreatment," Current Opinion in Psychiatry, vol. 14, no. 4, pp. 325-331, 2001.

[36] M. Testa, J. H. Hoffman, and J. A. Livingston, "Alcohol and sexual risk behaviors as mediators of the sexual victimization-revictimization relationship," Journal of Consulting and Clinical Psychology, vol. 78, no. 2, pp. 249-259, 2010.

[37] WHO, Alcohol use and sexual risk behaviour: a cross-cultural study in eight countries, World Health Organization, 2005. 